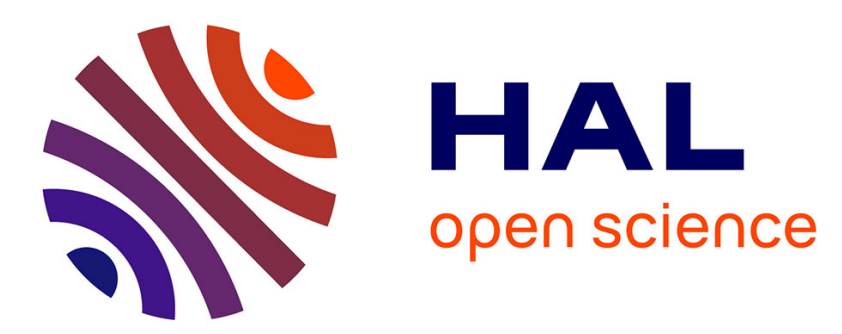

\title{
Towards a Collaborative Business Ecosystem for Elderly Care
}

\author{
Thais Andrea Baldissera, Luis M. Camarinha-Matos
}

\section{To cite this version:}

Thais Andrea Baldissera, Luis M. Camarinha-Matos. Towards a Collaborative Business Ecosystem for Elderly Care. 7th Doctoral Conference on Computing, Electrical and Industrial Systems (DoCEIS), Apr 2016, Costa de Caparica, Portugal. pp.24-34, 10.1007/978-3-319-31165-4_3 . hal-01438269

\section{HAL Id: hal-01438269 https://hal.inria.fr/hal-01438269}

Submitted on 17 Jan 2017

HAL is a multi-disciplinary open access archive for the deposit and dissemination of scientific research documents, whether they are published or not. The documents may come from teaching and research institutions in France or abroad, or from public or private research centers.
L'archive ouverte pluridisciplinaire HAL, est destinée au dépôt et à la diffusion de documents scientifiques de niveau recherche, publiés ou non, émanant des établissements d'enseignement et de recherche français ou étrangers, des laboratoires publics ou privés.

\section{(c)(1)}

Distributed under a Creative Commons Attribution| 4.0 International License 


\title{
Towards a Collaborative Business Ecosystem for Elderly Care
}

\author{
Thais Andrea Baldissera, Luis M. Camarinha-Matos \\ Faculty of Science and Technology and Uninova-CTS, NOVA University of Lisbon \\ Campus de Caparica, Portugal \\ tab@uninova.pt, cam@uninova.pt
}

\begin{abstract}
In fast changing environments, companies and organizations have to continuously adapt their operating principles in response to new business or collaboration opportunities in order to remain competitive. The growing demand for high-quality services is taking organizations to format their operations to offer more personalized service packages and seek collaboration with other stakeholders. Moreover, provision of personalized services depends on frequent contextual information analysis. In the case of elderly care, the use of assistive technology is expected to have a positive contribution to the diversity of required services that support aging well. Demographic trends show that the percentage of elderly population is increasing, while ageing entails several limitations, calling for assistance services adapted to the specific needs of each person. These needs can evolve along the ageing process, requiring an evolution of the care services. In this paper, we make an overview of related concepts and propose a personalized and evolutionary care services model supported on collaborative networking, context-awareness and Internet of Things.
\end{abstract}

Keywords: Collaborative Business Services, ICT and Ageing, Collaborative Networks, Context Awareness.

\section{Introduction}

In the last decades, one of the most important demographic changes in the history of humanity has been taking place: the aging of the global population. In fact, current trends $[1 ; 2]$ clearly suggest that elderly population will surpass young people in many regions of the world. This change is already a consolidated fact in countries such as Portugal, where the population over 60 years is $10 \%$ higher than people under 15 years old, a situation that was inversely proportional 30 years ago. By 2050, it is expected that the population over 80 years exceeds the young [2]. This situation seem to concern mainly the developed world, but it no exclusive theirs.

Current estimates indicate that $60 \%$ of elderly people live by themselves or in the company of another elderly person, and strive to guarantee their autonomy and perform their own duties. With continuous advances in medicine and wellness areas, people aspire to an active and enjoyable aging [1], although aging might entail several limitations due to physical and cognitive decay. In extreme cases, regular daily 
activities such as cooking, personal hygiene, housework, etc., might be affected [1;2].

Traditional approaches to deal with this problem require intense care from family. Relatives need to actively participate in the aging process and support elderly. As such, many people live with their family, especially when they begin to loose capabilities. Those who remain living alone either care for themselves or require caregivers to assist them on daily activities. Alternatively, the elderly may stay in nursing homes. All these changes can directly affect the senior life style [3].

The use of technology in assisting elderly is expected to have a positive contribution to overcome identified challenges by supporting a diversity of services that promote independent living [1;3-5]. However, most elderly people still face several barriers in an increasingly technological society. This fact puts older adults at a disadvantage, requiring that researchers and practitioners deliver more suitable products for this community $[3 ; 4 ; 6]$. For each elderly individual, specific care and assistance services might be necessary, according to his/her life context. A care service may be adequate for one elderly and completely useless for another one. As a single care organization can hardly meet all needs of each individual senior with the best services available in the market, collaboration between companies may be a promising way for delivery of integrated and personalized services.

In this context the main research question addressed by this work is: How to provide personalized and evolutionary collaborative care services for elderly in an effective and reliable way?

The pursued hypothesis is: Effective and reliable evolutionary services for elderly care can be provided if a suitable set of multi-provider business services are composed and integrated in the context of a collaborative network environment and supported by context awareness methods, mechanisms and systems.

In this paper, we propose a Collaborative Business Ecosystem Model for elderly care based on collaborative networking and relevant context-aware technologies that can be applied to personalization and evolution of care and assistance services. The Collaborative Networks paradigm (Section 3) supports provision of integrated services and helps services providers to acquire agility and better survive in market. In particular, we present collaborative business services in the elderly care domain and context-awareness technologies for personalization and evolution of care and assistance services. A Collaborative Business Ecosystem (CBE) Model (Section 4) gives the adequate organizational context for collaboration. Finally, we conclude (Section 5) with a discussion on the main advantages and concerns on emergent technologies for elderly care and assistance.

\section{Benefits from Cyber-Physical Systems}

It is expectable that with the increased intelligence in the new systems, interaction with technology becomes part of daily life for seniors, family members, caregivers and integrated service providers, while respecting the individual life context. Some examples of technological solutions with impact in aging well include smart devices, like wearable devices, sensors and associated software services that provide real-time data about an individual and the environment he/she lives in; a bracelet that uses a GPS sensor to set up a "safe zone" for people with cognitive disorders; an at-home 
patient-tracking device with a panic button for emergencies; cameras and sensors that capture movements, calculate body weight and make the measurement of heart-bit rate; and intelligent home appliances [9].

With advances in sensor technology, a growing number of sensors that communicate with each other with minimum human intervention will be attached to objects around us, generating a massive amount of data. Context-aware computing allows us to extract contextual information linked to sensor data so the interpretation can be done easily and more meaningfully [7; 8]. The adoption of context-aware analysis techniques, combined with smart devices and sensors, are likely to enable a great number of new care and assistance services. These technologies can be a strong ally in helping on the identification and analysis of the user's context in order to provide relevant inputs for the evolution of assistance services.

In the elderly care domain, context aware technologies supported by CPS can: (i) provide inputs to personalize or evolve the service based on multi-source contextual information, (ii) monitor individuals to provide best options and recommendation of services, (iii) enable businesses to redefine key aspects of their customer relationships, and (iv) cater direct interaction between senior and his/her living environment (devices and people) and services provided.

\section{Related Areas}

Collaborative Networks. In highly dynamic domains, such as health and personal services, companies are challenged to be able to efficiently interplay with multiple organizations to compose personalized offers without losing competitiveness and quality in their services. In such context, new collaborative strategies can facilitate the engagement and interaction of distinct stakeholders in any effort towards common or compatible goals. Advances in ICT, namely Internet and pervasive computing, have enabled or induced the emergence of new collaboration paradigms. However, the rapid formation of a collaborative network $(\mathrm{CN})$ to respond to a business opportunity faces a number of challenges, whereas two are most relevant: (i) the large heterogeneity of the autonomous participants involved in the process, in terms of their technological infrastructures, business practices, culture, etc., and (ii) the time needed to build trust [10]. To face these challenges, the concepts of Virtual Organization Breeding Environment and Collaborative Business Ecosystem were proposed [10].

Participation in collaborative networks has the potential of bringing benefits to the involved entities such as: survivability in a context of turbulence, reaching higher levels of agility, acquisition of a larger apparent dimension, access to new/wider markets and new knowledge, sharing risks and resources, joining of complementary skills, and better achieving common goals [10-12].

In the elderly care domain, CNs can: (i) provide organizational structures and governance models for groups of care and assistance stakeholders; (ii) support provision of integrated services; (iii) enable offering services tailored to each senior and his/her life style; (iv) facilitate composition of new services in line with new demands (current situation, specific requirements, new technologies); (v) facilitate lobbying \& market influence; (vi) provide a framework for organizing collaborative 
processes among stakeholders.

Collaborative Business Services. Research and development in elderly care services traditionally focused on the development of isolated services, often considering a single service provider and showing an excessive techno-centric flavor. However, to satisfy current demanding market challenges, organizations must collaborate to overcome their weaknesses and strengthen their expertise, so that they can offer better integrated and user-centric services, and gain competitive advantage [13]. Furthermore, in the elderly care context there is a need for personalized services that respect the individuality of each senior and the evolution of needs as senior's life context changes [8]. In order to support this perspective of service provision, the term Collaborative Business Ecosystem (CBE) can be adopted [14]. A CBE can assist in the integration of different services from distinct providers. For the elderly care domain the term collaborative business service can be named as Collaborative Care and Assistance Service. Such services can be seen as the result of collaboration among various stakeholders, including local communities, governmental institutions, care professionals, family and caregivers, and thus require a supporting collaboration environment.

Context Aware Technologies. Context awareness is about capturing a broad range of contextual attributes (such as the user's current position, activities, and surrounding environment) to better understand what the customer is trying to accomplish, and what services might be of interested [15]. According to Costa et al. [16] contextawareness seeks to exploit human-computer interactions by providing computing devices with knowledge of the users' environment, i.e., with context. Context awareness computing is a recent and development [9] which appears quite promising for the elderly care domain. Many recent technologies contribute to the development of context-aware solutions. Scoble and Israel [9] highlight five forces that have shaped and cooperated with the advances on context-aware technologies: Mobile, Social Media, Data, Sensors, and Location-based services. These forces can directly influence decisions through a context analysis and supported by a wide range of sensors, smart devices, and new evolutionary services. These devices in a communicating-actuating collaborative network are part of the IoT, where sensors and actuators blend seamlessly with the environment around us.

\section{Collaborative Business Ecosystem Model}

The proposed CBE model for elderly care includes:

Service Composition: A care service can be either a single (atomic) or integrated business service. Therefore, service provision can be done by a single entity or by several entities. Some entities participating in a composite service may already be a composite service provider. This leads to a hierarchical categorization of service providers. For instance, in Fig. 1 two providers deliver one collaborative service CS1, and three other service providers offer atomic services SS2, SS3, and SS4. CS1 is seen by the CBE like a simple service, which combined with other services, compose the personalized service CS2. This collaborative service (CS2) is provided to the customer as one composite service, delivered by a collective provider (i.e. a 
collaborative network).

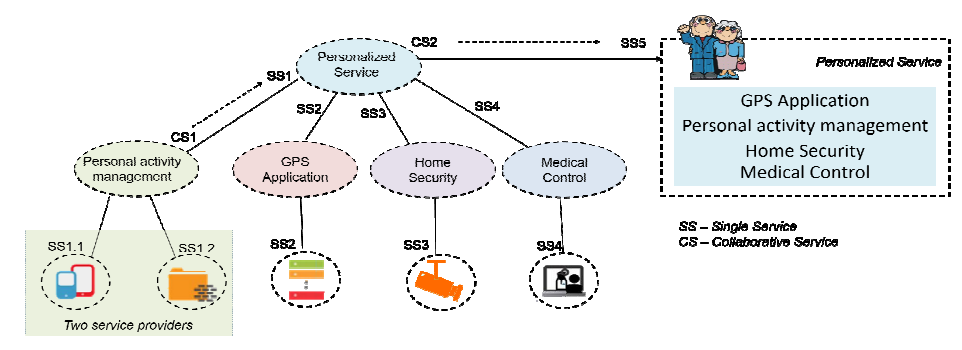

Fig. 1. Example of Creation of Composite Services from Providers of Distinct Types

Service Personalization and Evolution for Elderly Care: In the elderly care domain, personalization involves the analysis of the senior's life context. For instance, let us consider a senior, 68 years old that lives alone and still works in a company. The organization responsible for delivering care and assistance services identifies specific requirements for this context and builds a service package for this customer, including, for instance, adjusted working space and home security monitoring services. At a later stage in life additional needs are identified as he got (in this scenario) some chronic diseases, diabetes, and less vision. As such, new services need to be delivered, e.g. personal management notices for application of insulin, control of medication, and continuous health monitoring. One year later, he recovered from some disease and is now retired: his life context changed again. So the care and assistance provider organization identifies the new situation and adjusts the provided service. The customer does not need an adjusted working space in the company anymore and this service will be removed from the package, but a social program for meeting with friends and services allowing the participation in virtual professional senior communities is added to his package. In other words, the service package evolves to cope with the new life stage.

For each new context change, the care and assistance service provider organization shall analyze the situation (in collaboration will all relevant stakeholders), and evolve the service to fit that context. This perspective is illustrated in Fig. 2.

Under this perspective, the notion of evolutionary service $[7 ; 13 ; 17 ; 18]$ means that the provided service adapts to the senior's needs, to the environment and to any changes that affect the senior's life context. In the previous example, the care provider organization adjusts the service due to new senior's context requirements (e.g. when he retired). But this service evolution could also be done due to technological reasons, as sensors and devices are improving and becoming cheaper, or new technologies emerge better meeting the user needs. Additionally, market factors (companies may disappear or merge with others) or new governmental regulations may also lead to service evolution.

CBE Structure: The proposed CBE is based on the ARCON reference model [19] and the Ambient Assisted Living (AAL) Ecosystem concept [5], focusing on a care and assistance community of interacting entities, comprising both organizations and individuals participating in elderly care. It is aimed that the ecosystem community is 
supported by common operating principles and cooperation agreements, and also includes the basic profiles of all stakeholders [13].

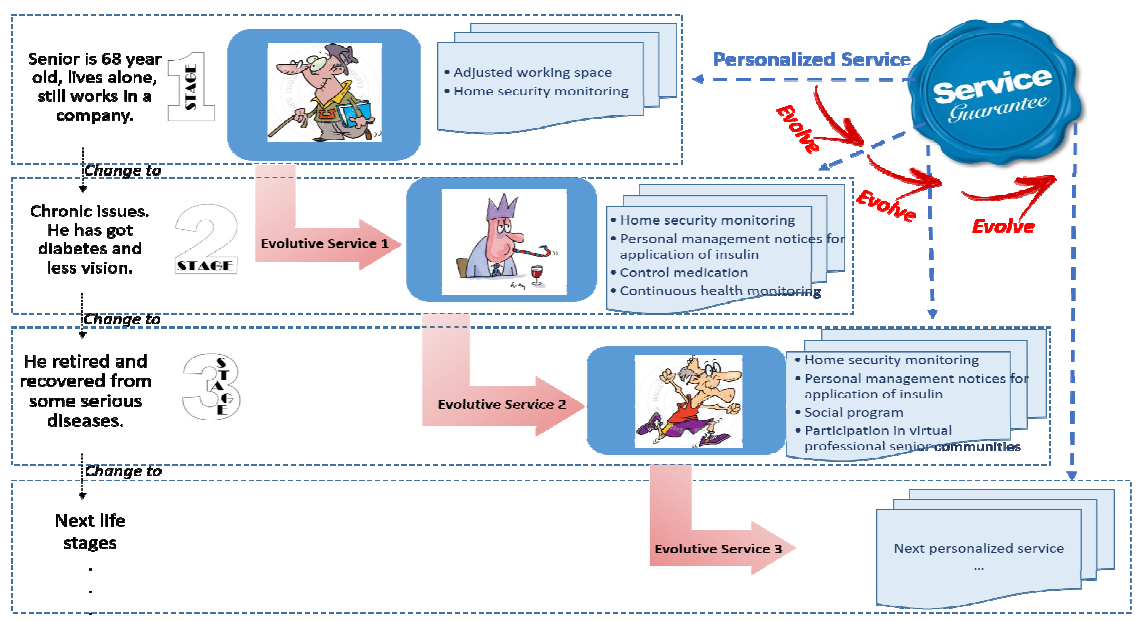

Fig. 2. Example of Personalized and Evolutionary Service Stages

In such ecosystem, as illustrated in Fig. 3, the main intervenient actors are divided into two groups:

Elderly Living Environment (ELE), representing the elderly costumers and their ambient and context, including informal caregivers such as family and friends, and all applications and devices with which they interact such as context aware devices;

Services Providers Environment (SPE), representing the care provision stakeholders with the goal to provide care and assistance services, facilitating support, companionship, all based on community participation with established trust. The SPE may include private companies and/or governmental institutions;

To operate the CBE, three main modules (Tab. 1) are considered:

Tab. 1. CBE Modules

\begin{tabular}{|c|c|c|}
\hline Module 1 - Service Design & Module 2 - Service Evolution & Module 3 - Service Runtime \\
\hline $\begin{array}{l}\text { Responsible for receiving service } \\
\text { requests from seniors and family } \\
\text { and searching the providers and } \\
\text { best services available for the } \\
\text { senior and his/her living } \\
\text { environment (ELE costumer). }\end{array}$ & $\begin{array}{l}\text { Responsible for analyzing sensorial } \\
\text { information and proposing a } \\
\text { personalized and evolutionary care } \\
\text { and assistance service for ELE } \\
\text { costumer; }\end{array}$ & $\begin{array}{l}\text { Responsible for notifying the } \\
S P E \text { and delivering to } E L E \\
\text { the care and assistance } \\
\text { services according to the } \\
\text { corresponding agreed terms. }\end{array}$ \\
\hline
\end{tabular}

Besides atomic business services, the CBE, with the characteristics of a Virtual Organizations Breeding Environment, also facilitates the rapid composition of business services into integrated business services, from one or several stakeholders, being thus one of the requirements that services are prepared to collaborate with each other [10]. Additionally, the planned CBE Structure considers that service descriptions are kept in a Service Catalogue, to be consulted whenever needed. 
The main goal of these functionalities (Fig. 3) is to support a middle layer between the Service Provider Environment and the Elderly Living Environment, supporting both parts in service provision. At a higher level, as the focus is on environments, the model is also intended to support service provision considering several customers' requirements under a context awareness perspective. That is, the generation of a multi-stakeholders consortium to provide services to a certain customer also takes into consideration historical data and requirements from ELE customers and their personal routines, the requirements of other customers that are in the same context (although each customer is treated respecting his/her individuality), the CBE can recommend some changes or additional services (evolutionary service).

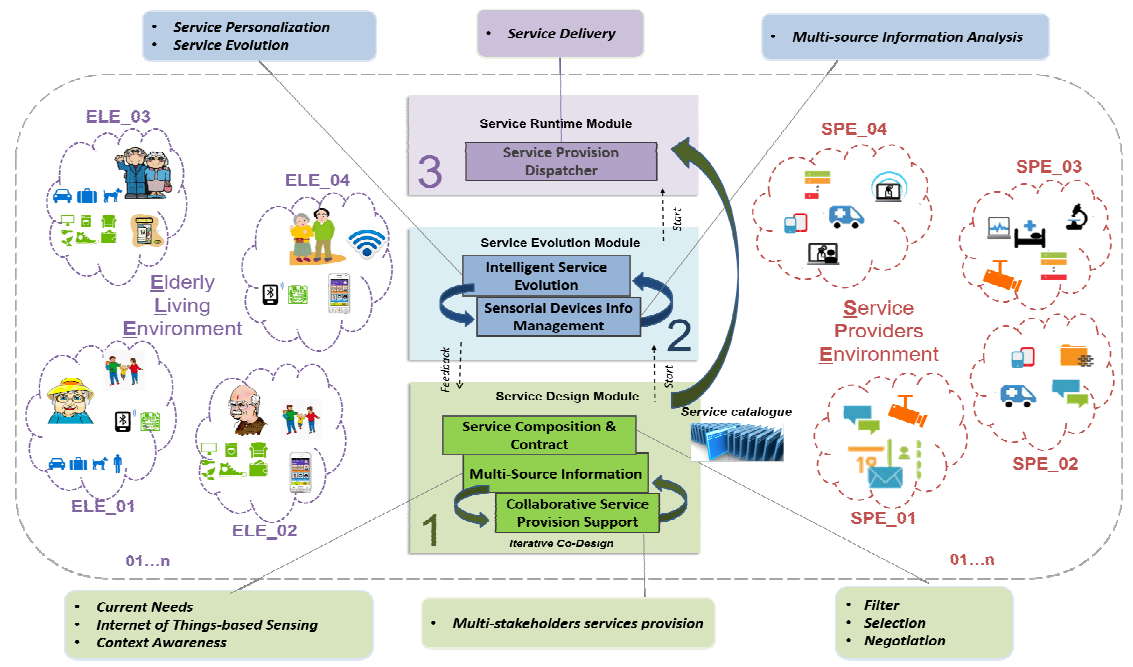

Fig. 3. Collaborative Business Ecosystem (CBE Structure)

Whenever a customer wants to make a request or subscribe a certain service, Module 1, through a Collaborative Service Provision Support activity, collects information about ELE costumer's care and assistance service requirements (through questionnaires, similarities with other customers, etc.) and verifies if a suitable service description is already defined in the service catalogue. If it is an undefined service, this module is responsible for conducting a new care and assistance service design involving the relevant stakeholders [13].

In the first interaction, after performing the data analysis, the CBE suggests a service to the senior and offers an experimental period. During this period, the Multisource Information activity collects sensorial data from multiple devices, such as: home sensorial information (motion detectors, pressure sensors, etc.); mobile sensorial information (mobile phones, wearable/ubiquitous devices/ computing, etc.); and medical devices (mobile electrocardiogram, blood glucose monitoring systems, etc.) and helps the Collaborative Service Provision Support activity to store the new description in the service catalogue (iterative co-design). This service represents the 
first evolution of the service based on context awareness analysis. Furthermore, Module 1 initiates a negotiation round with suitable service providers in order to create a consortium capable of fulfilling the request in the best optimized manner. Due to the characteristic of the ELE customers, the mentioned optimization can also include sensorial and contextual information of other ELE customers, so that SPE can fulfill the request considering other activities that are already being carried out in the similar contexts.

Fig. 4 illustrates an adapted i* Rationale Strategic Model for the Service Design Module (illustrative example), including the main dependencies of this layer with other actors and systems.

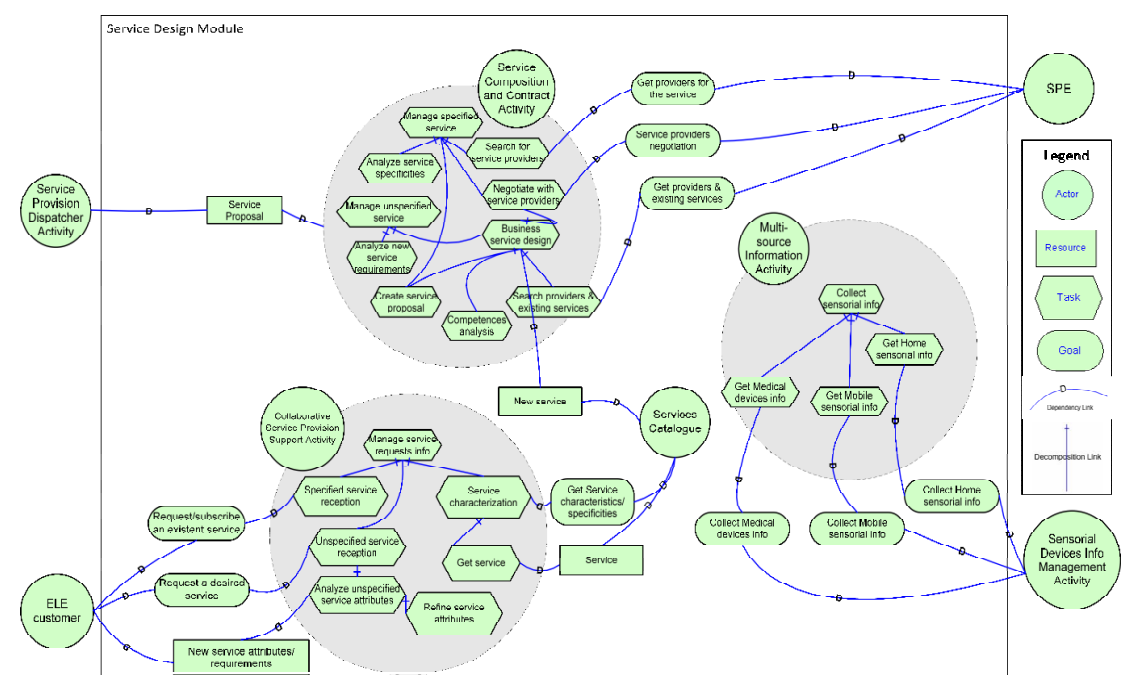

Fig. 4. Adapted i* Rationale Strategic Model for the Service Design Module

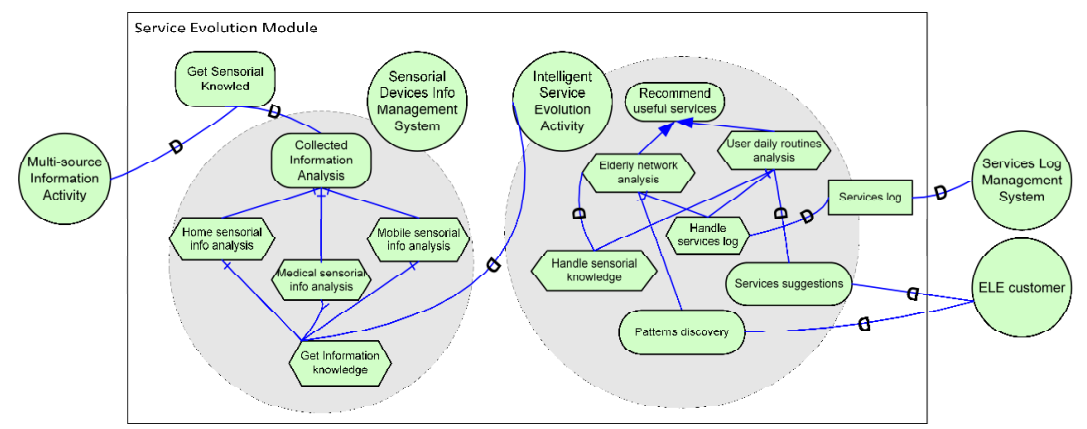

Fig. 5. Adapted i* Rationale Strategic Model for the Service Evolution Module

Module 2, Service Evolution, is responsible for proposing a personalized and 
evolutionary care and assistance service for the ELE costumer through data analysis (current needs, IoT-based sensing and, context awareness). The Sensorial Devices Information Management System gets information from the Multi-Source Information activity and analyzes these data. The result is sent to Intelligent Service Evolution activity which, by using relevant information, is able to recommend and/or suggest changes in evolutionary services for each ELE customer. Types of input information include: (i) sensorial information, essentially for context-awareness; (ii) relevant information from the ELE customer, to verify if additional services are necessary; (iii) analysis of the ELE customer's daily habits to recommend or suggest a care and assistance services adapted to the corresponding routines; and (iv) analysis of ELE to discover new patterns in ELE customer's behavior. Fig. 5 shows a preliminary adapted $i^{*}$ Rationale Strategic Model for Service Evolution Module, with the main dependencies of this module and the other actors and systems.

The suggested evolutionary care and assistance service implies a SPE provider (or several) for service provision for the ELE customer. Module 3 delivers the care and assistance service. Also, this module is responsible for service report to SPE.

Fig. 6 shows an adapted i* Rationale Strategic Model for Service Runtime Module, with the main dependencies of this layer and the other actors and systems.

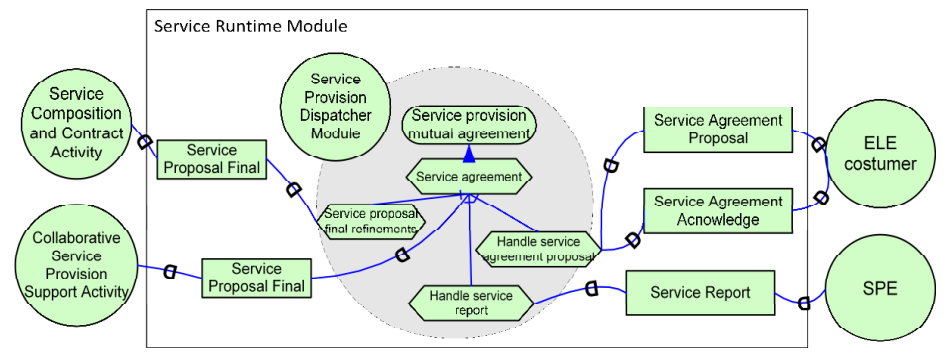

Fig. 6. Adapted i* Rationale Strategic Model for the Service Runtime Module

\section{Conclusions and Future Work}

In the era of IoT, many services will promote the extension of capabilities of elderly people for active aging. In this paper we highlight the design of a CBE model for elderly care based on collaborative networking and context-awareness to support active and productive aging. The adoption of context-aware analysis techniques, combined with smart devices and sensors, will enable a great number of seamless and, evolutionary and personalized services. As the intelligence in new systems grows, the technology becomes more interactive and gradually will be part of daily life of seniors, family members, caregivers and integrated service providers. While envisioned as a revolution on services, it is important to recognize that the economic growth alone will not improve older people's well-being and specific policies are required to address the implications of aging. Many computer tasks are still 
characterized by having high cognitive demands and, for this reason, it is important to carefully handle age-related changes on cognitive skills, when designing systems that target older adults. Because of the importance of improving the management and delivery of health care and social services, ICT plays a key role on developing quality of life of older people. Nevertheless, such initiatives are expected to assist on the mitigation of situations of isolation and loneliness, and improve family and community relationships. This paper represents the first phase of $\mathrm{PhD}$ and future work will rely on the progress of the CBE development and definition of mechanisms for personalization and evolution of services, as well as system's validation through tool prototype, publications, simulation and formulation of case studies (scenarios), comparison with other proposals and discussion with/assessment by stakeholders in elderly care.

Acknowledgments. This work has been funded in part by the Center of Technology and Systems and the Portuguese FCT-PEST program UID/EEA/00066/2013 (Impactor project), and by the Ciência Sem Fronteiras and Erasmus Mundi project (Brazil and European Commission).

\section{References}

1. Kearney, A. T. (2013). Understanding the Needs and Consequences of the Ageing Consumer. The Consumer Goods Forum. Retrieved 10/05/2015, 2015, from https://www.atkearney.com/documents/10192/682603/Understanding+the+Needs+ and+Consequences+of+the+Aging+Consumer.pdf/6c25ffa3-0999-4b5c-8ff1afdca0744fdc

2. HelpAgeInternational. (2014). Global AgeWatch Index 2014. Retrieved 10/03/2015, from http://www.helpage.org/global-agewatch/

3. Czaja, S. J., \& Lee, C. C. (2009). Information Technology and Older Adults. . In A. Sears \& J. A. Jacko (Eds.), Human-Computer Interaction: Designing for Diverse Users and Domains (pp. 18-30). Florida: CRC Press.

4. Alwan, M., Wiley, D., \& Nobel, J. (2007). A program of the American Association of Homes and Services for the Aging (AAHSA) (B. S. o. C. Foundation Ed.). Washington, DC

5. Camarinha-Matos, L. M., Ferrada, F., Oliveira, A. I., Rosas, J., \& Monteiro, J. N. (2013). Integrated Care Services in Ambient Assisted Living. IEEE 15Th Int. Conf. on e-Health Networking, Applications and Services (Healthcom 2013), Lisbon, 197-201.

6. Cresci, M. K., Yarandi, H. N., \& Morrell, R. W. (2010). Pro-nets versus no-nets: Differences in urban older adults' predilections for internet use. Educational Gerontology, 36(6), 500-520. 
7. Hong, J., Suh, E.-H., Kim, J., \& Kim, S. (2009). Context-aware system for proactive personalized service based on context history. Expert Systems with Applications, 36(4), 7448-7457. doi: http://dx.doi.org/10.1016/j.eswa.2008.09.002

8. O’Grady, M. J., Muldoon, C., Dragone, M., Tynan, R., \& O’Hare, G. M. (2010). Towards evolutionary ambient assisted living systems. Journal of Ambient Intelligence and Humanized Computing, 1(1), 15-29.

9. Scoble, R., \& Israel, S. (2014). Age of Context: mobile, sensors, data and the future of privacy. USA: Patrick Brewster Press.

10. Camarinha-Matos, L. M., Afsarmanesh, H., \& Boucher, X. (2010). The Role of Collaborative Networks in Sustainability. In Collaborative Networks for a Sustainable World, IFIP AICT series Vol. 336, pp. 1-16: Springer Berlin Heidelberg.

11. Crispim, J. A., \& de Sousa, J. P. (2010). Partner selection in virtual enterprises. International Journal of Production Research, 48(3), 683-707.

12. Bititci, U., Garengo, P., Dörfler, V., \& Nudurupati, S. (2012). Performance measurement: Challenges for tomorrow. I. J. of Management Reviews, 14(3), 305327.

13. Camarinha-Matos, L. M., Rosas, J., Oliveira, A. I., \& Ferrada, F. (2015). Care services ecosystem for ambient assisted living. Enterprise Information Systems, 9(5-6), 607-633.

14. Graça, P., \& Camarinha-Matos, L. (2015). The Need of Performance Indicators for Collaborative Business Ecosystems. In Technological Innovation for CloudBased Engineering Systems, IFIP AICT series, Vol. 450, pp. 22-30: Springer Berlin Heidelberg.

15. Lee, W.-P. (2007). Deploying personalized mobile services in an agent-based environment. Expert Systems with Applications, 32(4), 1194-1207.

16. Costa, P. D., Pires, L. F., van Sinderen, M., \& Rios, D. (2004). Services Platforms for Context-Aware Applications. In P. Markopoulos, B. Eggen, E. Aarts \& J. Crowley (Eds.), Ambient Intelligence (Vol. 3295, pp. 363-366): Springer Berlin Heidelberg.

17. Xu, X., \& Wang, Z. (2011). State of the art: business service and its impacts on manufacturing. Journal of Intelligent Manufacturing, 22(5), 653-662.

18. LeadingAge (2011). A Look into the Future: Evaluating Business Models for Technology-Enabled Long-Term Services and Supports. Retrieved 11/04/2015, from 
36 T. A. Baldissera and L. M. Camarinha-Matos

www.leadingage.org/uploadedFiles/Content/About/CAST/CAST_Scenario_Planni ng.pdf

19. Camarinha-Matos, L. M., \& Afsarmanesh, H. (2007). A comprehensive modeling framework for collaborative networked organizations. Journal of Intelligent Manufacturing, 18(5), 527-615. 